\title{
Knowledge and Practice of Nurses About the Control and Prevention of Nosocomial Infections in Emergency Departments
}

\author{
Mozhgan Kalantarzadeh ${ }^{1}$; Esmaeil Mohammadnejad ${ }^{2,}$; Seyyedeh Roghayeh Ehsani ${ }^{3}$; \\ Zahra Tamizi $^{4}$ \\ ${ }^{1}$ Department of Medical Surgical, Faculty of Nursing and Midwifery, Islamic Azad University, Kerman Branch, Kerman, IR Iran \\ 2 Department of Nursing, Students' Research Committee, Shahid Beheshti University of Medical Sciences, Tehran, IR Iran \\ ${ }^{3}$ Department of Nursing, Imam Khomeini Clinical and Hospital Complex, Tehran University of Medical Sciences, Tehran, IR Iran \\ ${ }^{4}$ Department of Nursing, University of Social Welfare and Rehabilitation Sciences, Tehran, IR Iran \\ ${ }^{*}$ Corresponding author: Esmaeil Mohammadnejad, Department of Nursing, Students' Research Committee, Shahid Beheshti University of Medical Sciences, Tehran, IR Iran. Tel: +98- \\ 2166936626, Fax:+98-2166936626, E-mail: asreno1358@yahoo.com
}

Received: February 16, 2014; Revised: June 7, 2014; Accepted: June 10, 2014

Background: Basic infection control measures in any nursing setup can reduce the rates of healthcare-associated infections. Reducing the risk of infection and using the prevention principles are in the realm of nursing.

Objectives: The current study aimed to evaluate the level of knowledge and practices on infection control among the nursing staff.

Patients and Methods: In this cross-sectional study 224 nurses were selected by random sampling from three teaching hospitals. A questionnaire was used to collect data. The questionnaire included three parts: demographic characteristic, level of knowledge, and practices among the nursing staff. Data were analyzed by SPSS software.

Results: The result of the research showed that the majority of participants were female(53.6\%), married(80.4\%), had BS degree(89.3\%) and had the working experience between 11 and 20 years (51.8\%); 41.1\% and 33.03\% of the participants respectively had intermediate and high level of knowledge about infection control. Also the result showed that (75.8\%) had intermediate level of performance in this field. There was a significant correlation between sex and performance of the participants $(\mathrm{P}=0.014)$.

Conclusions: According to the obtained results, the majority of nurses participating in the study had an intermediate level of knowledge and practice of infection control. There is a need to develop a system of continuous education for all the categories of nursing staff.

Keywords:Nosocomial infection; Nurse; Knowledge

\section{Background}

Treatment measures and therapy cares are concomitant with positive and have unfavorable determinants and consequences of any economic, productive, sanitary, environmental and social performance. Hospitals had developed some permanent and reliable services in their organization. According to this issue, the health is as a final product of treatment goals in organization, side effects of treatment such as infects is more considerable and the time of ramifications is more important in hospital organization (1). The Nosocomial infections (NIs) afflict a considerable number of patients all over the world and are among the major risks and causes of death in treatment centers and hospitals of the world. Despite the attempts to prevent such infections, the problem continues to cause death and increase the costs of sanitary treatments (2-5). The healthcare-associated infections (HAIs) were defined by the CDC/ National Healthcare Safety Network (NHSN) Surveillance as a localized or systemic condition resulted from an adverse reaction to the presence of an infectious agent(s) or its toxin(s) (6) that occurs during a hospital admission 48 hours or more after hospital admission or within 30 days after discharge, for which there is no evidence that the infection was present or incubating at admission, and meets body site-specific criteria (7-9).

The NIs cause mental stresses, disability, paralysis, and decrease the quality of patients' lives (10). An estimate of the annual cost of treatment for HAIs ranges from $\$ 4.5$ billion to $\$ 11$ billion and HAIs contributed 88000 deaths in the U.S. in $1995(11,12)$. Some 1\% of these infections are mortal and some $4 \%$ contribute to patients' deaths (10). About $50 \%$ of the patients undergoing different surgeries return to treatment centers and sometimes to the same hospital; nearly $23 \%$ of these visits are caused by NIs (13). The problems of NIs and the ways to prevent them are influenced by factors such as employing aggressive methods, repeated changes in medical and surgical methods, changes in medical compounds, antibiotic treatment and formation of resistant micro-organisms (14). Hospital personnel, especially the nurses play an important role in spreading the infection and they are considered as key members of managing and controlling the hospital infections; therefore, nurses must have correct, up-to-

Copyright ( ) 2014, Infectious Diseases and Tropical Medicine Research Center; Published by Kowsar. This is an open-access article distributed under the terms of the Creative Commons Attribution-NonCommercial 4.0 International License (http://creativecommons.org/licenses/by-nc/4.0/) which permits copy and redistribute the material just in noncommercial usages, provided the original work is properly cited. 
date and appropriate scientific information regarding varieties of hospital infections, their effects on afflicting patients, death toll and increased hospital costs, recognition of people at risk and also the criteria to prevent and control (15). Nurses are the largest therapeutic team in hospitals $(16,17)$. On the other hand, nurses' knowledge and practice regarding sanitary conditions play an essential role to guarantee the individual and ultimately social health, increased level of nurses knowledge positively affects their performance (16). To control hospital infections, some measures should be taken in order to offer proper sanitary and therapeutic services through developing policies, controlling and evaluating conducted operations and permanent and continuous surveys.

\section{Objectives}

The current study aimed to evaluate the level of knowledge and practices on infection control among the nursing staff.

\section{Patients and Methods}

\subsection{Research Design and Context}

The present study was conducted through a descriptive cross-sectional framework on 224 nurses employed in the emergency departments of the three hospitals of Tehran University of Medical Sciences (TUMS), selected by simple random sampling in the year 2012-2013. The inclusion criteria in the research was at least one year of job experiences, and holding a bachelor degree and the exclusion criteria was the unwillingness of subjects to participate in this research.

\subsection{Measurement Tools}

The data collection tool was a three-part questionnaire. The first part of this questionnaire included the demographic features (age, gender, educational certificate, employment status, job, participation record in the infection control workshop during the recent year); the second part included 20 questions concerning knowledge about the process of infection, the effective factors to prevent Nis, types of infections, and the third part included 20 questions about self-reporting the practice of re-state in the areas of personal protection tools, hand hygiene, using disinfectants and safe injections. Face and content validity of the questionnaire were assessed by the previous studies, books, and through asking 10 members of the Faculty of Nursing of TUMS to comment on the questionnaire and considering their correctional comments. The reliability of the questionnaire was determined using Cronbach's alpha test $(r=0.81)$ for the knowledge section and $(r=0.79)$ for practice section. Knowledge of the subjects under study in infection control were assessed by a scoring system in which correct and incorrect answers provided for the questions were allocated one and zero point respectively. Participants' total scores ranging between 0 and 20 were classified into three categories of weak (0-6), intermediate (7-13) and good (14-20) and the knowledge score ranged between 0 and 20. To analyze the practice, the scoring was conducted through a five-degree Likert scale (Never = zero point, rarely=one point, sometimes $=$ two points, often $=$ three points and always=four points). After summing up, the obtained scores were classified into three levels of weak Practice (0-40), intermediate performance (41-60) and good performance (61-80) and the practice scores ranged between 0 and 80 .

\subsection{Statistical Analysis}

Data analysis was performed using the Statistical Package for Social Sciences (SPSS v.16.0; SPSS Inc., Chicago, Illinois, USA). Responses to knowledge and practice questions were reported as descriptive statistics (frequency, mean, median and standard deviation). The percentage score was calculated as total achieved scores divided by total maximum scores. Chi-square was used to compare the differences in percentage. $\mathrm{P}<0.05$ was considered as level of significance.

\subsection{Ethical Considerations}

To conduct the current study permission was obtained from the Ethics Committee of the Imam Khomeini Complex Hospital. Other ethical issues in the study included the assurance of confidentiality and anonymity of the participants and their responses. All participants were informed about the purposes and methods of the study. They were also informed that participation in the study is voluntary, so they could refuse to participate or withdraw from the study at any stage. Lastly, the participants were asked to sign a written consent.

\section{Results}

The results of the research showed that among 224 nurses who participated in the research, (53.6\%) were women, (89\%) had bachelor degree, (80.4\%) were married, and (14.2\%) were head nurses and supervisors. The

Table 1. The Distribution of the Studied Units Based on the Level of Knowledge and Practice in Controlling Nis

\begin{tabular}{lc}
\hline Degree & No. (\%) \\
\hline Knowledge & $72(33.03)$ \\
\hline Weak (0-6) & $94(41.09)$ \\
\hline Intermediate (6-13) & $58(25.9)$ \\
\hline Good (14-20) & \\
\hline Performance & $34(15.1)$ \\
\hline Weak(0-40) & $170(75.8)$ \\
\hline Intermediate (40.1-60) & $20(8.9)$ \\
\hline Good (60.1-80)
\end{tabular}


Kalantarzadeh $M$ et al.

Table 2. The Distribution of Studied Units Based on Self-Reporting Practice Concerning Prevention and Control NIs a

\begin{tabular}{lccccc}
\hline Variable & Always & Often & Sometimes & Rarely & Never \\
\hline Using personal protection tools & 22.3 & 18.7 & 32.1 & 16.07 & 1.7 \\
Hand hygiene & 19.6 & 7.1 & 33.9 & 25.8 & 13.3 \\
Using disinfectants & 43.75 & 10.8 & 7.1 & 21.4 & 16.07 \\
Safe injections & 66.07 & 6.2 & 15.1 & 8.03 & 4.4 \\
$\begin{array}{l}\text { Prevention of respiratory and } \\
\text { urinary infections }\end{array}$ & 37.5 & 16.9 & 20.5 & 15.1 & 18.7 \\
Wound protection & 10.7 & 15.1 & 36.6 & 31.2 & 6.2 \\
\hline
\end{tabular}

a Data are presented as \%.

mean age of participants in the research was $29 \pm 4.7$ and (51.8\%) had job experience of 11 to 20 years with the mean of $11 \pm 1.5$ years. Seventy-two people (32.5\%) had participated in infection control workshops at least once. Results showed that (41.07\%) of the study subjects had intermediate knowledge and (75.8\%) of nurses had intermediate performance (Table 1). It was also shown that among the study subjects, the best tested performance was safe injections (Table 2).

Data analysis showed a significant relationship between the mean of nurses' knowledge score and their job experience mean $(r=0.25, \mathrm{P}<0.05)$. The chi-square test showed no significant relationship between sex and knowledge of the studied people, whereas this test indicated a significant relationship between sex and practice of the personnel under study $(\mathrm{P}=0.014)$. Spearman correlation test showed no significant relationship between knowledge and practice level of the nurses in the whole research population.

\section{Discussion}

Nurses can prevent infection transferring among the patients of a hospital with proper disinfecting the skin, wearing gloves and masks, changing infusion sets, applying prudential measures, proper isolation, using the principles of standard cautions, observing hand hygiene, preventing accidental contact of hand with needle-stick and avoiding the infected respiratory discharges (19). However, the results of the current study suggested that the majority of units under study had inadequate knowledge about controlling hospital infections. Nurses' knowledge about hospital infection prevention and control is reported differently and sometimes paradoxically. In McBride study in America, most of the nurses (65\%) had no proper knowledge about controlling hospital infections (20). A research carried out among the nurses of England showed that general knowledge about Nis controlling was inadequate (21). The above-mentioned results are in line with the results obtained from the study by Chan et al. (22) in America, Angelillo in Italy (18) and Bota in Iran (23). This problem highlights the necessity to consider the improvement of the relevant knowledge of the nursing personnel. Nurses' degree of knowledge concerning hospital infections depends on various factors, including personal and educational features, attending educational courses and also management and motivation factors; as Gold stressed on continuous educational courses (24). The performance of the investigated units was intermediate in $75.8 \%$ of the nurses regarding hospital infections control, which was consistent with the study by Moghaddasian et al. in Tabriz, Iran (9); but was not in line with the study by Raeis Karimian et al. in Yasuj, Iran that indicated the proper performance of the majority of nurses (25). Perhaps the reason for this inconsistency lies in educating the studied units and too busy and tired from excessive work. Results showed no significant relationship between knowledge level and practice. Other researches also show that in spite of good knowledge, performances are weak (26); having knowledge will not always result in enhanced performance because environmental facilities and conditions influence the performance as well $(27,28)$. In order to develop proper performance, in addition to adequate knowledge, other factors such as suitable motivation, control system, and permanent evaluation are effective (29). The results of this research showed that despite their knowledge regarding the necessity of hand hygiene nurses did not observe hand hygiene in the treatment procedures. The conducted investigations revealed the reasons for violation of hand hygiene and not observing sterile points during treatment procedures by nurses included having too much business and lack of adequate time, negative attitude of nurses, lack of direct contact or lack of contact with the infected patients and also avoiding contact with disinfectants or detergents (30). The nurses in hospital departments have an important role in decreasing the risk of hospital infections and can contribute effectively by washing hands, and ensuring the accurate application of medical prescriptions (12). A nurse can play an important role in controlling hospital infections via updated knowledge, enhanced attitude and professional behaviors (18). The studies on nurses ` behavior based on their self-reporting, reported a higher level of practice compared to those studies on 
the basis of observed behavior. Of course, the studies involving comparison of the observed and self-reported behaviors of infection control, including hand hygiene, demonstrated that employees and nurses always report more than what they really do (31). Therefore, in order to establish a proper behavior by proper performance of nurses and other members of the treatment team concerning hospital infection control and prevention, it is necessary to provide departments with conditions and facilitation for appropriate performance; for example, adequate human resources, suitable equipment, permanent and updated education etc., and then according to the World Health Organization recommendation, the behaviors should be monitored through continuous observation (32). On the basis of the current study findings, it can be concluded that there exists a positive and direct relationship between knowledge and practice. It indicates that with improved knowledge, practice can be also improved, which should be of major concern in nurses. Results of a number of studies in the area of infection control suggested that educational programs with the subject of controlling hospital infections result in improving the participation and attention of nurses and employees with respect to hospital infection and an important part of nurses programs is allocated to learning hospital infections (33-35). Finally, the current study results emphasized to develop a national database system to assess knowledge and practices regarding basic infection control protocols, which provide the necessary data to targeted courses and educational interventions.

\section{Acknowledgements}

Authors wish to thank all infection control supervisors and nurses who cooperated in this study.

\section{References}

1. Ceballos K, Waterman K, Hulett T, Makic MB. Nurse-driven quality improvement interventions to reduce hospital-acquired infection in the NICU. Adv Neonatal Care. 2013;13(3):154-63.

2. Ruza F, Alvarado F, Herruzo R, Delgado MA, Garcia S, Dorao P, et al. Prevention of nosocomial infection in a pediatric intensive care unit (PICU) through the use of selective digestive decontamination. Eur J Epidemiol. 1998;14(7):719-27.

3. Couto RC, Pedrosa TM, Tofani Cde P, Pedroso ER. Risk factors for nosocomial infection in a neonatal intensive care unit. Infect Control Hosp Epidemiol. 2006;27(6):571-5.

4. Dominguez TE, Chalom R, Costarino AT, Jr.. The impact of adverse patient occurrences on hospital costs in the pediatric intensive care unit. Crit Care Med.2001;29(1):169-74.

5. Vosylius S, Sipylaite J, Ivaskevicius J. Intensive care unit acquired infection: a prevalence and impact on morbidity and mortality. Acta Anaesthesiol Scand. 2003;47(9):1132-7.

6. Horan TC, Andrus M, Dudeck MA.CDC/NHSN surveillance definition of health care-associated infection and criteria for specific types of infections in the acute care setting. Am J Infect Control 2008;36(5):309-32.

7. Kouchak F, Askarian M. Nosocomial infections: the definition criteria. Iran J Med Sci. 2012;37(2):72-3.

8. Klevens RM, Edwards JR, Richards CL, Jr., Horan TC, Gaynes
RP, Pollock DA, et al. Estimating health care-associated infections and deaths in U.S. hospitals, 2002. Public Health Rep. 2007;122(2):160-6.

9. Moghaddasian S, Zamanzadeh V, Parvan K, Allah Bakhshian M. Knowledge, Attitude and Practice of ICU Nurse about Nosocomial infection control in Teaching Hospital of Tabriz. Iran J Nurse. 2010;23(64):17-28.

10. Otani K, Kurz RS. The impact of nursing care and other health care attributes on hospitalized patient satisfaction and behavioral intentions. J Healthc Manag. 2004;49(3):181-96.

11. Stone PW, Larson E, Kawar LN. A systematic audit of economic evidence linking nosocomial infections and infection control interventions:1990-2000. Am J Infect Control. 2002;30(3):145-52.

12. Ocran I, Tagoe DNA. Knowledge and attitude of healthcare workers and patients on healthcare associated infections in a regional hospital in Ghana. Asian Pac J Trop Dis. 2014;4(2):135-9.

13. Sadagiani M. Organization and Hospital Management. 1999: 35-50.

14. Aylifle GAJ, Fraise AP, Geddes AM, Mitchel K. Control of Hospital In fection. 5th edLondon: Arnold; 2004.

15. Cheraghi MA, Nejad EM, Begjani J, Rabirad N, Ehsani SR, Kaji MA Knowledgeand Attitudes of Nurses Regarding HIV/AIDS (Tehran-2010). Iran J Clin Infect Dis. 2011;6(3).

16. Ehsani SR, Cheraghi MA, Nejati A, Salari A, Esmaeilpoor AH, Nejad EM. Medication errors of nurses in the emergency department. $J$ Med Ethics Hist Med. 2013;6:11.

17. Mohammad Nejad E, Jafari S, Mahmoodi M, Begjani J, Roghayyeh Ehsani S, Rabirad N. Hepatitis B virus antibody levels in high-risk health care workers. Hepat Mon. 2011;11(8):662-3.

18. Angelillo IF, Mazziotta A, Nicotera G. Nurses and hospital infection control: knowledge, attitudes and behaviour of Italian operating theatre staff. J Hosp Infect. 1999;42(2):105-12.

19. Smeltzer and Bare.. Text Book of medical surgical nursing.Philadelphia: J.B.Lippincott; 2004.

20. McBride A. Health promotion in hospitals: the attitudes, beliefs and practices of hospital nurses. J Adv Nurs. 1994;20(1):92-100.

21. Wolf R, Lewis D, Cochran R, Chesley R. . Nursing Staff Perceptions of Methicillin-Resistant Staphylococcus aureus and Infection Control in a Long-Term Care Facility. Am J Clin Dermatol. 2008;9(5):342-6.

22. Chan R, Molassiotis A, Chan E, Chan V, Ho B, Lai CY, et al. Nurses knowledge of and compliance with universal precautions in an acute care hospital. Int J Nurs Stud. 2002;39(2):157-63.

23. Bota R, Jamali MS, Azeem Q. Knowledge and self-perceived practices regarding infection control among nursing students of a tertiary care hospital. Am J Clin Dermatol. 2013;41(11):1143-4.

24. Gould D, Chamberlain A. Infection control as a topic for wardbased nursing education. J Adv Nurs. 1994;20(2):275-82.

25. Raeis Karimian F, Rostami Nejad A. [A survey an knowledge and practice of nursing staff on controlling nosocomial infections in Yasouj hospital]. Armaghan-e-denesh J. 2003;8(31):41-50.

26. Figueroa JP, Brathwaite AR, Wedderburn M, Ward E, Lweis-Bell K, Amon JJ, et al. Is HIV/STD control in Jamaica making a difference? AIDS. 1998;12 Suppl 2:S89-98.

27. van Gemert-Pijnen J, Hendrix MG, van der Palen J, Schellens PJ. Performance of methicillin-resistant Staphylococcus aureus protocols in Dutch hospitals. Am J Infect Control. 2005;33(7):37784.

28. Ghabrah TM, Madani TA, Albarrak AM, Alhazmi MA, Alazraqi TA Alhudaithi MA, et al. Assessment of infection control knowledge, attitude and practice among healthcare workers during the Hajj period of the Islamic year 1423 (2003). Scand J Infect Dis. 2007;39(11-12):1018-24.

29. Motamed N, BabaMahmoodi F, Khalilian A, Peykanheirati M Nozari M. Knowledge and practices of health care workers and medical students towards universal precautions in hospitals in Mazandaran Province. East Mediterr Health J. 2006;12(5):653-61.

30. Haji Amiri P. [Hand- Washing]. Irn J Nurs . 2001;1(7):10-1.

31. Jenner EA, Fletcher BC, Watson P, Jones FA, Miller L, Scott GM. Discrepancy between self-reported and observed hand hygiene behaviour in healthcare professionals. J Hosp Infect. 2006;63(4):418-22. 


\section{Kalantarzadeh $\mathrm{M}$ et al.}

32. Sax H, Allegranzi B, Chraiti MN, Boyce J, Larson E, Pittet D. The World Health Organization hand hygiene observation method. Am J Infect Control. 2009;37(10):827-34.

33. Bennett N, Boardman C, Bull A, Richards M, Russo P, Clin Epid M. Educating Smaller Rural Hospital Infection Control (IC) Nurses, Victoria, Australia. Am J Infect Control. 2006;34(5):64-6.

34. Tavolacci MP, Ladner J, Bailly L, Merle V, Pitrou I, Czernichow P.
Prevention of nosocomial infection and standard precautions: knowledge and source of information among healthcare students. Infect Control Hosp Epidemiol. 2008;29(7):642-7.

35. Suchitra JB, Lakshmi Devi N. Impact of education on knowledge, attitudes and practices among various categories of health care workers on nosocomial infections. Indian J Med Microbiol. 2007;25(3):181-7. 